\title{
PREVALENCE OF HYPERTENSION AND ITS ASSOCIATED RISK FACTORS AMONG AMONG DRIVERS IN NORTH CHENNAI-A CROSS SECTIONAL STUDY
}

\section{Dr Aravind Raj G $\mathrm{V}^{*}$}

\section{Dr Umashankar R}

Junior Resident, Department of general medicine, Sree Balaji Medical college and Hospital, no 7, works road, Chrompet, Chennai,Tamil nadu, India-600 044. *Corresponding Author Assistant Professor, Department of general medicine, Sree Balaji Medical college and Hospital, no 7, works road, Chrompet, Chennai,Tamil nadu, India-600 044.

ABSTRACT Background: Hypertension is a leading cause of morbidity and mortality worldwide. We aimed to estimate the prevalence of hypertension in a population of drivers in Chennai, India.

Methods: The study population included drivers working in Chennai city. Blood pressure, height, and weight of subjects were measured, and relevance was obtained using a structured questionnaire.

Results: Age varied from 30 to 60 years with the mean age of 43 years. Among 400 drivers studied, $33 \%$ of them were hypertensive and based on diastolic and systolic blood pressure, $15 \%$ of them were in pre-hypertensive and $28 \%$ of the were in stage $-1 \mathrm{HTN}$ and $31 \%$ of them were in stage- 2 HTN. Obesity, Smoking, alcohol and history diabetes play a major risk factor the development of hypertension

Conclusion: Prevalence of hypertension was high among drivers. Life style may play a key role in the development of hypertension along with duration of work and behavioral pattern.Prevention strategies need to be emphasized in this kind of occupational group.

KEYWORDS : hypertension, drivers, prevalence

\section{INTRODUCTION}

The World Health Organization is developing a Global Plan of Action, for 2013-2020, to provide a roadmap for country-led action for prevention and control of non-communicable diseases and controlling their key risk factors. Around 41 million people are killed every year by non-communicable diseases (NCDs), equal to 71 percent of all deaths worldwide. Fifteen million people die annually from NCD between the ages of 30 and 69 . More than $85 \%$ of these "premature" deaths occur in countries with low and medium incomes. The majority of NCD deaths or 17.9 million people worldwide are due to cardiovascular diseases, followed by cancers (9.0 million), respiratory diseases (3.9 million), and diabetes (1.6 million). Over 80 percent of all premature NCD deaths are accounted for by these four disease groups. (1) Cardiovascular diseases (CVD) are the major cause of mortality globally, as well as in India. More individuals die from CVDs annually than from any other source. An estimated 17.7 million people died from CVDs in 2015 , representing 31 percent of all global deaths, according to the WHO. An estimated 7.4 million of these deaths were due to coronary heart disease and 6.7 million were due to stroke. Tobacco use, physical inactivity, the harmful use of alcohol and unhealthy diets all increase the risk of dying from a NCD.(1)Hypertension can be avoided by treating lifestyle risk factors such as tobacco use, unhealthy diet and obesity, physical inactivity and unsafe use of alcohol using population-wide interventions, including most cardiovascular diseases. People with or at high cardiovascular risk (due to the existence of one or more risk factors such as hypertension, diabetes, hyperlipidaemia or already known disease) with cardiovascular disease need early diagnosis and treatment, as needed, through therapy and medicinal products.(2)Skilled driving in a single body pose, under proximity to friction, vehicle emissions, and noise, is correlated with long hours. In addition, the job is carried out in a setting that requires continuous diligence. There are several particular diseases for which substantially elevated mortality and morbidity risks have been identified. A high relative risk for ischemic heart disease has also been correlated with skilled driving.(3) In recent decades, studies have shown that staff in the transport industry are at greater risk of poor diet and sedentary behaviour. In particular, bus drivers have higher mortality , morbidity, and absenteeism rates due to obesity. Drivers have a higher risk of noncommunicable diseases, including hypertension and obesity, in comparison to other working professionals, according to a study released in Pune, April 10 (IANS). Hence, this study was undertaken to measure the prevalence of Hypertension among lorry drivers and to find out the associated risk factors.

\section{METHODS}

A cross-sectional study was carried out in the drivers in Chennai. The study was conducted during September and December, 2019. The estimated sample size for our study was 88 . But we decided to study all male bus drivers enlisted in the Corporation bus stand giving consent to participate in the study. Male with the age of above 30 was included in this study. If they have any chronic illness like cancer, renal problem was excluded from the study.Stratified random sampling was used from each zone of Chennai city.Sample size of 400 was included in this study. By WHO definition, Hypertension is known as high or raised blood pressure, is a condition in which the blood vessels have persistently raised pressure as systolic blood pressure diastolic blood pressure. According to Joint National Committee's 7th (JNC 7) recommendation systolic pressure more than or equal to $140 \mathrm{mmHg}$ and diastolic blood pressure more than or equal to $90 \mathrm{mmHg}$ was defined Hypertension. In this study both the systolic blood pressure greater than $140 \mathrm{mmHg}$ and diastolic blood pressure greater than 90 only were considered as Hypertensive. As per WHO criteria or history of previously known disease and pre-hypertension was defined as SBP 120-139 mmHg or DBP $80-89 \mathrm{mmHg}$. Three readings will be taken and a third reading were taken if there is a difference of more than 10 $\mathrm{mm}$ of $\mathrm{Hg}$ in the first two readings and note down as blood pressure measurement. Drivers personel information like their medical history, lifestyle, and occupation was obtained by interview method using a pretested semistructured questionnaire. BP was measured manually using a mercury column sphygmomanometer and stethoscope by the auscultatory method. We measured the subjects' height and weight, from which the body mass index (BMI) was calculated. The weight was measured (closest to $1 \mathrm{~kg}$ ) using a beam type weighing scale. Height was measured (nearest to $1 \mathrm{~cm}$ ) with the subject in an erect position against a vertical surface. Hypertensives were referred for medical care and prehypertensives were advised lifestyle modification and BP monitoring.Informed written consent was obtained from all subjects before including the study. All the collected data were entered in SPSS-24 ver. Quantitative variables were summarized as frequency, percentage and mean and qualitative variables were summarized as proportions. Quantitative variables were tested for statistical significance using Student's -test.

\section{RESULT}

A total of 400lorry drivers in Chennai Regions were included for this study.The baseline characteristics of the participants are showed in the below table. (Table-1)

Table:1. Basic Demographic Characteristics Of The Driver

\begin{tabular}{|l|l|l|l|}
\hline Variables & Characteristics & Frequency & Percent(\%) \\
\hline Age & $30-35$ & 79 & 18.9 \\
\cline { 2 - 4 } & $36-40$ & 56 & 13.4 \\
\cline { 2 - 4 } & $41-45$ & 78 & 18.6 \\
\cline { 2 - 4 } & $46-50$ & 80 & 19.1 \\
\cline { 2 - 4 } & $51-55$ & 102 & 24.3 \\
\cline { 2 - 4 } & $56-60$ & 24 & 5.7 \\
\hline Education & Primary school & 03 & 0.7 \\
\hline \multicolumn{2}{|l|}{ Secondary school } & 230 & 58.5 \\
\hline
\end{tabular}


Volume - 10 | Issue - 11 | November - 2020 | PRINT ISSN No. 2249 - 555X | DOI : 10.36106/ijar

\begin{tabular}{|l|l|l|l|}
\hline \hline \multirow{5}{*}{ Religion } & Higher school & 140 & 34.4 \\
\cline { 2 - 4 } & UG & 19 & 4.5 \\
\cline { 2 - 4 } & PG & 06 & 1.4 \\
\cline { 2 - 4 } & Diploma & 02 & 0.5 \\
\hline \multirow{5}{*}{ Marital Status } & Hindu & 369 & 93.1 \\
\cline { 2 - 4 } & Christian & 22 & 5.3 \\
\cline { 2 - 4 } & Muslim & 08 & 1.7 \\
\hline Family Type & Single & 15 & 3.6 \\
\cline { 2 - 4 } & Married & 370 & 95.0 \\
\cline { 2 - 4 } & Separated & 02 & 1.0 \\
\cline { 2 - 4 } & Widower & 02 & 0.5 \\
\hline \multirow{5}{*}{ Driving Experience } & Nuclear & 261 & 64.7 \\
\cline { 2 - 4 } & Joint & 140 & 35.3 \\
\cline { 2 - 4 } & Less than 10yrs & 220 & 56.1 \\
\cline { 2 - 4 } & More than 10 yrs & 180 & 43.9 \\
\hline
\end{tabular}

In this study majority of the drivers fall in the age group of 51-55 years with mean age of 43 years. Around 58\% completed their secondary school level education. $95 \%$ of them were from nuclear family and $64 \%$ of them were married.

Table-2: Type Of Diet Taken By Drivers

\begin{tabular}{|l|l|l|}
\hline Dietary pattern & Frequency & Percent(\%) \\
\hline Vegetarian & 23 & 5.3 \\
\hline Non -Vegetarian & 377 & 94.7 \\
\hline Total & 400 & 100.0 \\
\hline
\end{tabular}

Around $95 \%$ of the drivers are non-vegetarian.(Table-2)

Table-4: Prevalence Of Outside Food Consumption

\begin{tabular}{|l|l|l|}
\hline Outside food taken & Frequency & Percent (\%) \\
\hline Yes & 130 & 31.5 \\
\hline No & 270 & 68.5 \\
\hline Total & 400 & 100.0 \\
\hline
\end{tabular}

Around $69 \%$ of them usually taken out side food.(Table-4)

Table-5 : Tobacco Usage

\begin{tabular}{|l|l|l|}
\hline Tobacco usage & Frequency & Percent(\%) \\
\hline Smoking tobacco & 66 & 15.75 \\
\hline Smokeless tobacco & 60 & 16.46 \\
\hline Both & 8 & 1.90 \\
\hline None & 266 & 65.87 \\
\hline Total & 400 & 100 \\
\hline
\end{tabular}

Drivers are having the habit of chewing tobacco to avoid stress. In this study, unexpectedly $65 \%$ of them were not consumed tobacco and only $45 \%$ of them were using smokeless and smoke and both.

Table-6: Alcohol Consumption

\begin{tabular}{|l|l|l|}
\hline Alcohol & Frequency & Percentage(\%) \\
\hline Yes & 239 & 57.0 \\
\hline Past H/oalcoholic & 60 & 14.31 \\
\hline No & 101 & 21.63 \\
\hline
\end{tabular}

Total of 239 (57\%) of them were alcoholic, 14 of them had the previous history of alcoholic and $23 \%$ of them were not alcoholic.(Table-6)

\section{Table-7: Type Of Vehicle}

\begin{tabular}{|l|l|l|}
\hline Heavy vehicle & Frequency & Percent(\%) \\
\hline Yes & 60 & 15.8 \\
\hline No & 340 & 84.2 \\
\hline Light vehicle & & \\
\hline Yes & 118 & 30.5 \\
\hline No & 282 & 69.5 \\
\hline
\end{tabular}

\section{Table-8: Antropometric Measurement}

\begin{tabular}{|l|l|l|}
\hline BMI & Frequency & Percent(\%) \\
\hline Underweight & 4 & 1.0 \\
\hline Normal & 163 & 38.9 \\
\hline Overweight & 196 & 46.8 \\
\hline Obese & 56 & 13.4 \\
\hline Total & 419 & 100.0 \\
\hline
\end{tabular}

Majority of the Drivers were fall under Overweight 196(46.8\%) and 56(13.4\%) were under Obese.

Table-9 : Prevalence Of Hypertension Among Drivers

\begin{tabular}{|l|l|l|}
\hline BP Status & Frequency & Percent(\%) \\
\hline Normo-Hypertensive & 271 & 67.1 \\
\hline \hline
\end{tabular}

\begin{tabular}{|l|l|l|}
\hline Hypertensive & 129 & 32.9 \\
\hline Total & 400 & 100.0 \\
\hline
\end{tabular}

The above table shows that Around 33\% of them are hypertensive (Table-9)

Table-10: Histroy Of Diabetes

\begin{tabular}{|l|l|l|}
\hline Known DM & Frequency & Percent(\%) \\
\hline Yes & 80 & 21.0 \\
\hline No & 320 & 79 \\
\hline Total & 400 & 100.0 \\
\hline
\end{tabular}

The above table shows the history of diabetes, which shows that around $21 \%$ of them were diabetic among drivers.(Table-10)

Table -11: Type Of Hypertension

\begin{tabular}{|l|l|l|}
\hline Based on SBP/DBP & Frequency & Percent(\%) \\
\hline Normal & 99 & 24.82 \\
\hline Pre_Hypertensive & 61 & 15.51 \\
\hline Stage1_hypertensive & 110 & 28.40 \\
\hline Stage2_Hypertensive & 130 & 31.26 \\
\hline Total & 400 & 100.0 \\
\hline
\end{tabular}

From the above table we can observe that around $15 \%$ of them are under risk of developing hypertension and $28 \%$ of them are in stage -1 and $31 \%$ of them were in stage- 2 hypertension Table :History of Diabetes Mellitus(DM)

About $88(21.0 \%)$ of the driver's were the Known case of Diabetes mellitus it was reported by them during data collection.

Table-12 : Sleeping Pattern In Drivers

\begin{tabular}{|l|l|}
\hline Descriptive statistics & Sleep (hrs) \\
\hline Mean & 5.48 \\
\hline Median & 6.00 \\
\hline Std. Deviation & 1.34 \\
\hline Minimum & 2 \\
\hline Maximum & 10 \\
\hline
\end{tabular}

The mean sleep of the drivers are only 5.48 hours with SD of 1.44 .

Table-13 : Association Of Experience

\begin{tabular}{|l|l|l|l|}
\hline Experience & Hypertensive & Non-Hypertensive & P-Value \\
\hline$<10 \mathrm{yrs}$ & 178 & 57 & 0.000 \\
\hline$>10 \mathrm{yrs}$ & 103 & 81 & \\
\hline & 281 & 138 & \\
\hline
\end{tabular}

While comparing the years of experience and hypertension there was a statistically stron association observed with the p-value of 0.000 .

\section{DISCUSSION}

We aimed to report the prevalence and special risk factors of HTN among occupational bus drivers, an especially vulnerable group, through our research. It was found that $33 \%$ of the drivers was hypertensive. The only other research done in India on transit vehicle operators deals with HTN among Nagpur's autorickshaw drivers, with a recorded prevalence of 35.14 percent(4). The overall prevalence of HTN in the study group is much higher than the reported pooled prevalence of about $16-20 \%$ in India . $(5,6)$ Just two studies from South Asia on HTN in drivers have been published so far.In the study the driver's in the age group of 51-55years were high which is similar to the study done by Satheesh B. C. et al a study conducted among bus drivers in Bangalore city, 226(45\%) out of 500 drivers were in 40-49 year age group and in the present study the age group above 50 years were $102(24 \%)$ and this age group contradicts with $57(17 \%)$ in $\geq 50$ years age group in the Bangalore study.(24) In this study there is no association between diet pattern and hypertension. Mostly drivers taken food outside in hotels and mess about 287(68.5\%). It was like the study by SharvananEshwaran Udaya et al, s about dietary factors 144(58.1\%) drivers had a regular habit of eating outside food when they are on duty $60(24.6 \%)$ of drivers also gave history of extra salt consumption in the form of pickle, pappad, dry fish etc.(7) In this study around $31 \%$ of them are having the habit of tobacco consumption and there was a stron association observed with hypertension. Aroung $57 \%$ of tehm were alcholic which is compared with NFHS-IV data shows Men are more likely to drink alcohol (47\%) than to use tobacco.HTN and diabetes mellitus often go hand in hand as part of the metabolic syndrome. However, we findan association between the two in the present study.In the study the number of Known hypertension cases were $46(33.3 \%)$ and a Newly detected hypertensive cases were 
92(66.7\%).If the drivers are working long time as driver have a risk of developing hypertension. The main strength of our research was that there were multiple BP readings obtained. All the measurements were done in the field. Concerning proper medical treatment, subjects with elevated BP were advised. One of our limitations was that the abdominal circumference that correlates better with HTN than with BMI was not measured.In conclusion, the prevalence of HTN is very high among drivers. At the heart of the issue lies a close-to-urban unhealthy lifestyle gained as part of their work. In the future, they are at risk of developing coronary artery disease, stroke, and chronic renal disease. This will cause substantial mortality and morbidity, decrease economic and social participation, and burden the health system of both their families and the country. For lifestyle, all occupational drivers should be screened.

\section{REFERENCES}

1. Noncommunicable diseases [Internet]. WHO. 2018 [cited 2018 Jun 19]. Available from: Noncommunicable diseases [Internet]. WHO. 2018 [cited 2018 Jun 19]. Available from: http://www.who.int/news-room/fact-sheets/detail/noncommunicable-diseases

2. Family History \&amp; Your Risk for High Blood Pressure (Hypertension) $\mid$ cdc.gov [Internet]. 2018 [cited 2018 May 30]. Available from: https://www.cdc.gov/ bloodpressure/family_history.htm

3. Department of Evaluation and Applied Research Tamil Nadu. Tamil Nadu - An Economic Appraisal 2011-12 to 2013-14. 2015;193-213. Available from: http://www. tn.gov.in/dear/Health.pdf

4. S. S. Chaudhary, M. M. Nagargoje, S. S. Kubde, S. C. Gupta, and S. K. Misra, "Prevalence of cardiovascular diseases risk factors among auto-rickshaw drivers," Indian Journal of Community Health, vol. 22, no. 1-2, pp. 32-34,2011.

5. S. Guha, A. Ghosh, N. Chatterjee et al., "Risk factors for coronary heart disease in Indians: a case-control study from Eastern India,” Indian Heart Journal, vol. 57, no. 6, pp. $738-740,2005$

6. S. K. Das, K. Sanyal, and A. Basu, "Study of urban community survey in India: growing trend of high prevalence of hypertension in a developing country," International Journal of Medical Sciences, vol. 2, no. 2, pp. 70-78, 2005 .

7. Sharvanan Eshwaran Udayar1, Rajesh Kumar K2, Praveen Kumar BA1, Sivachandiran Vairamuthu3 ST. Study of Cardiovascular Risk Factors Among Transport Drivers in Rural Area of Andhra Pradesh. Natl J Community Med. 2015;6(4):566-70. 